\title{
Attitudes of Nurses Caring for Children with Disabilities
}

\section{Kathleen Cervasio ${ }^{1 *}$}

Long Island University, School of Nursing, 1 University Plaza, Brooklyn, NY 11201, USA

The Institute of Medicine (2003) challenged all healthcare professions to adopt curricula content focused on the current healthcare needs in the United States. Many medical schools and schools of health professions struggle to implement this challenge. The Surgeon General has identified children with disabilities as a vulnerable and disenfranchised group relating to health prevention, promotion, and treatment usage. The Robert Wood Johnson Foundation funded an initiative, Quality and Safety in Education for Nurses (2007), to close the gap between nursing education and practice, focused on knowledge, attitudes, and skills for nurses. Attitudinal barriers are the most recognized impediment to health care for children with disabilities [1]. Attitudes of nurses play a pivotal role in the care of children with disabilities and their families. Diminutive attention is furnished to disability education in undergraduate nursing curriculum in the United States. International healthcare researchers have suggested that education affects the attitudes of healthcare professional students, therefore affecting patient care outcomes [2]. Disability education warrants position in nursing curriculum in the United States.

International research has concentrated on the attitudes of healthcare professionals toward disabled adults and rarely toward children with disabilities [3]. Attitudes are hypothetical constructs that embody what an individual views as positive, negative or neutral; they are comprised from affective, behavioral, and cognitive responses and can be transformed by persuasion and experience [4]. Simply put an attitude is a mental state, belief, or a predisposition to behavior [5]. This statement implies attitudes are cognitive, effective, and behavioral in response to a stimulus. Attitudes, like all psychological constructs, are observed indirectly in human responses [6]. If attitudes affect the actions of nurses caring for patients, then it is appropriate to measure the attitudes of nurses, evaluate the implications for nursing practice, and recommend interventions. The attitudes of nurses play a direct role in the quality of the patient care experience.

Attitude plays an influential role in the quality of clinical services rendered by healthcare professionals [7]. Disabled individuals report dissatisfaction with healthcare professional contact stemming from inadequate personal experiences described as patronizing and disempowering practices [8]. Services to children with disabilities are described as inexpert, fragmented, and poorly coordinated [8]. It is critical for the nursing profession to provide insight into the nursing curriculum experiences as it relates to disability issues and examine how nursing students conceptualize disability content in curricula to improve nursing care [2]. Theoretically, knowledge, skills, and attitudes of nursing students and faculty are intertwined in nursing education. Faculty attitude are one of the most important variables affecting the education of professionals who will care for children with disabilities [9].

Nursing has and will continue to play a pivotal role in caring for all children and their families [10]. Attitudes of professional nurses can positively or negatively affect their approach to patient care [11]. In order to provide quality nursing care to children with disabilities nurses need formal curricula content and clinical exposure. Disability researchers have focused on measuring the attitudes of healthcare professionals toward adults with various disabilities. Researchers have rarely focused on the attitudes of nursing students toward children with disabilities in the United States. Attitudes of nursing students are directly affected both by faculty and by curricula content [11]. Disability education warrants position in nursing curriculum in the United States. Attitudes have a profound impact on the delivery of nursing care for children with disabilities [11].

\section{References}

1. Greiner A, Knebel E, Institute of Medicine (2003) Health Professions Education: A Bridge to Quality. National Academies Press, Washington DC.

2. Rao S (2004) Faculty attitudes and students with disabilities in higher education: A literature review. College Student Journal 38.

3. Seccombe JA (2007) Attitudes towards disability in an undergraduate nursing curriculum: the effects of a curriculum change. Nurse Educ Today 27: 445-451.

4. Matziou V, Galanis P, Tsoumakas C, Gymnopoulou E, Perdikaris P, et al (2009) Attitudes of nurse professionals and nursing students towards children with disabilities. Do nurses really overcome children's physical and menta handicaps? Int Nurs Rev 56: 456-460.

5. Burns K (2007) Definition: attitude.

6. Altmann TK (2008) Attitude: A concept analysis. Nursing Forum 43: 144-150.

7. Albarracin D, Johnson BT, Zanna MP (2005) The handbook of attitudes Lawrence Erlbaum Associates, New Jersey.

8. Dorji S, Solomon P (2009) Attitudes of health professionals toward persons with disabilities in Bhutan. Asia Pacific Disability Rehabilitation Journal 20: 32-42.

9. Heaton M (2002) Maria's stories. International paediatric nursing conference providing quality care for children with disabilities.

10. Parasuram K (2006) Variables that affect teachers' attitudes towards disability and inclusive education in Mumbai, India. Disability \& Society 21: 231-242.

11. Noreuil M (2007) Nursing excellence for families and children. Nursing Education Perspectives, 28(3), 158-160.

Corresponding author: Dr. Kathleen Cervasio, Long Island University School of Nursing, 1 University Plaza, Brooklyn, NY 11201, USA, E-mail: Kathleen.Cervasio@liu.edu

Received May 17, 2012; Accepted May 19, 2012; Published May 21, 2012

Citation: Cervasio K (2012) Attitudes of Nurses Caring for Children with Disabilities J Nurs Care 1:e103. doi:10.4172/2167-1168.1000e103

Copyright: @ 2012 Thorstensson S, et al. This is an open-access article distributed under the terms of the Creative Commons Attribution License, which permits unrestricted use, distribution, and reproduction in any medium, provided the original author and source are credited. 